\title{
Synthesis and characterization of $\beta$ type solid solution in the binary system of $\mathrm{Bi}_{2} \mathrm{O}_{3}-\mathrm{Eu}_{2} \mathrm{O}_{3}$
}

\author{
O TURKOGLU*, M SOYLAK and I BELENLI ${ }^{\dagger}$ \\ Department of Chemistry, 'Department of Physics, Faculty of Art and Science, Erciyes University, \\ 38039 Kayseri, Turkey
}

MS received 3 September 2002

\begin{abstract}
We have investigated $\mathrm{Bi}_{2} \mathrm{O}_{3}-\mathrm{Eu}_{2} \mathrm{O}_{3}$ binary system by doping with $\mathrm{Eu}_{2} \mathrm{O}_{3}$ in the composition range from 1 to 10 mole\% via solid state reactions and succeeded to stabilize $\beta-\mathrm{Bi}_{2} \mathrm{O}_{3}$ phase which is metastable when pure. Stability of $\beta-\mathrm{Bi}_{2} \mathrm{O}_{3}$ polymorph was influenced by heat treatment temperature. Tetragonal type solid solution was obtained in 3-6 mole\% addition range when annealed at $750^{\circ} \mathrm{C}$ and the range was 2-7 mole \% when annealed at $8^{\circ}{ }^{\circ} \mathrm{C}$. We have also carried out investigations on lattice parameters, microstructural properties and elemental compositions of this $\beta$ type solid solution for each doping ratio. Lattice parameters increased with amount of $\mathrm{Eu}_{2} \mathrm{O}_{3}$ addition. Our experimental observations strongly suggested that oxygen deficiency type non-stoichiometry is present in doped $\beta$ type solid solutions.
\end{abstract}

Keywords. Bismuth trioxide polymorphs; solid solution; $\mathrm{Bi}_{2} \mathrm{O}_{3}-\mathrm{Eu}_{2} \mathrm{O}_{3}$ binary system.

\section{Introduction}

Bismuth trioxide has four polymorphs: monoclinic (or pseudo-orthorhombic) $\alpha$-form, face centred cubic $(f c c)$ $\delta$-form, tetragonal $\beta$-form and body centred cubic $(b c c)$ $\gamma$-form. Of these polymorphs, only $\alpha-\mathrm{Bi}_{2} \mathrm{O}_{3}$ is a stable phase of pure $\mathrm{Bi}_{2} \mathrm{O}_{3}$ at room temperature (Takahashi et al 1977; Chiodelli et al 1994; Oniyama and Wahlbeck 1998). When pure $\alpha$ phase is heated to about $730^{\circ} \mathrm{C}$, transition to the $\delta-\mathrm{Bi}_{2} \mathrm{O}_{3}$ occurs and this phase is stable only between $730^{\circ} \mathrm{C}$ and melting point of $825^{\circ} \mathrm{C}$. Large thermal hysteresis effects are present upon cooling, and $\delta$ phase transforms to one of the two intermediate phases which are $\beta$-form (formed at $650{ }^{\circ} \mathrm{C}$ ) and $\gamma$-form (formed at $639^{\circ} \mathrm{C}$ ). The $\gamma$-phase can be obtained by controlled cooling of $\beta-\mathrm{Bi}_{2} \mathrm{O}_{3}$. The last two phases are metastable and they usually transform to the $\alpha$ phase in the temperature range $650-500^{\circ} \mathrm{C}$ (Harwig and Gerards 1978; Miyayama and Yanagida 1986; Oniyama and Wahlbeck 1998). The $\gamma$ and $\beta$ forms can only be obtained as stable phases at room temperature by addition of small amounts of other dopant oxides, i.e. $\mathrm{Y}_{2} \mathrm{O}_{3}, \mathrm{MoO}_{3}, \mathrm{CoO}, \mathrm{Sb}_{2} \mathrm{O}_{3}$, $\mathrm{WO}_{3}, \mathrm{SrO}, \mathrm{CaO}, \mathrm{La}_{2} \mathrm{O}_{3}, \mathrm{~V}_{2} \mathrm{O}_{5}$ and $\mathrm{Gd}_{2} \mathrm{O}_{3}$ (Takahashi et al 1977; Miyayama et al 1982; Miyayama and Yanagida 1986; France et al 1997; Ling et al 1998; Turkoglu et al 1998, 1999; Turkoglu and Soylak 2002).

$\beta-\mathrm{Bi}_{2} \mathrm{O}_{3}$ type crystal structure is a two-dimensional superstructure of the $\delta-\mathrm{Bi}_{2} \mathrm{O}_{3}$ structure. $\beta-\mathrm{Bi}_{2} \mathrm{O}_{2.5}$ has

\footnotetext{
*Author for correspondence
}

been reported as a non-stoichiometric phase in the space group $P 42_{1} c$ with lattice constants of $a=7 \cdot 75$, and $c=5.63 \AA$, while the lattice parameters of the stoichiometric $\beta-\mathrm{Bi}_{2} \mathrm{O}_{3}$ phase which is also in the same space group are $a=7.74$ and $c=5.63 \AA$. The locations of the bismuth ions in the crystal structures are nearly identical but large differences for the locations of oxygen ions have been reported (Harwig 1978; Medernach and Snyder 1978). Gattow and Schütze (1964) have observed that the $\beta-\mathrm{BiO}_{1.5}$ and $\beta-\mathrm{BiO}_{1.75}$ phases prepared by quenching maintain their structures in non-stoichiometric compositions. Lattice parameters of non-stoichiometric $\beta$ $\mathrm{BiO}_{1.5}$ and $\beta-\mathrm{BiO}_{1.75}$ phases are $a=10.95, c=5.63 \AA$ and $a=10.96, c=5.64 \AA$, respectively (Gattow and Schütze 1964). It has been reported in the references mentioned above that the non-stoichiometric $\beta$ phases have oxygen ion vacancies while for stoichiometric compounds of this type, all particular cationic and anionic sites are fully occupied.

In the present work, we intended to stabilize the metastable $\beta$ phase of $\mathrm{Bi}_{2} \mathrm{O}_{3}$ at room temperature by addition of $\mathrm{Eu}_{2} \mathrm{O}_{3}$ and to investigate the range of addition ratio and heat treatment temperature for stabilization. Moreover, some crystallographic and microstructural properties of the obtained single $\beta$ phase samples were examined.

\section{Experimental}

The powder samples were prepared by mixing appropriate amounts of $\alpha-\mathrm{Bi}_{2} \mathrm{O}_{3} \quad\left(99.99 \%\right.$ Merck) and $\mathrm{Eu}_{2} \mathrm{O}_{3}$ (99.99\% Merck) without further purification. The solid 
oxide mixtures that contained increasing amounts of $\mathrm{Eu}_{2} \mathrm{O}_{3}$ from 1 to 10 mole\% were prepared by mixing and homogenizing in an agate mortar. These oxide mixtures were calcined at $650^{\circ} \mathrm{C}$ for $48 \mathrm{~h}$. The calcined powders were ground and heat-treated at $700^{\circ} \mathrm{C}$ for $48 \mathrm{~h}$. These oxide powders were further heat treated for $48 \mathrm{~h}$ at 750 and $800^{\circ} \mathrm{C}$ with an intermediate grinding. Heat treatments were performed as loose powders, in gold crucibles, in air. At the end of each heat treatment procedure, annealed powders were slowly cooled in the furnace by switching off (uncontrolled). Following the heat treatment step at $800^{\circ} \mathrm{C}$, powder samples were heated to $830^{\circ} \mathrm{C}$ in a vertical tube furnace, kept at that temperature for $15 \mathrm{~min}$ in air then quenched by dropping the sample into ice-water mixture.

X-ray powder diffraction (XRD) patterns were taken after every heat treatment step in order to check phase formation. XRD data were collected with Bruker AXS D8 advanced diffractometer using a Bragg-Brentano geometry with graphite monochromator $\mathrm{CuK}_{\alpha}$ radiation $(\lambda=$ $1.5405 \AA$ ) operated at $40 \mathrm{kV}$ and $40 \mathrm{~mA}$. The divergence and receiving slits of 1 and $0 \cdot 1 \mathrm{~mm}$, respectively were located on the diffractometer. Diffraction patterns were scanned by $0.002^{\circ}$ steps over the angle range of $10^{\circ}-90^{\circ}$

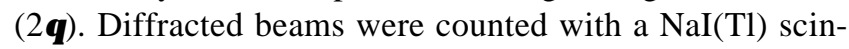
tillation detector and the obtained XRD data were compared with the reference data.

Microstructural aspects and microprobe analysis of formed samples were studied employing a LEO 440 scanning electron microscope (SEM). Microprobe analysis data were taken from flat surface of the pressed samples. Ten analyses were made from different regions of each sample at high magnification and mean values from these measurements were used for calculations. SEM images of the prepared samples were taken from loose powders, free outer surfaces and fracture surfaces of the pressed and annealed samples.

The grain size of the crystallites (mean crystalline diameter, $D$ ) is calculated using Scherrer's equation which is given below (West 1998)

$$
D=(0.9 \lambda) /(\beta \cos \theta)
$$

where $\lambda$ is the wavelength of X-rays, $\theta$ the Bragg's angle of XRD and $\beta$ the broadening of diffraction line measured at half its maximum intensity (radians). In this study, $\beta$ values of the particular planes of the single phase samples were found by using Bruker AXS D8 TOPAS 2 software.

\section{Results and discussion}

In $\left(\mathrm{Bi}_{2} \mathrm{O}_{3}\right)_{1-x}\left(\mathrm{Eu}_{2} \mathrm{O}_{3}\right)_{x}$ system, experimented solid solution region and obtained phases either single or heterogeneous, are presented in table 1 , depending on the reaction temperature. Heat treatment temperatures below $750^{\circ} \mathrm{C}$ and quenching experiments produced the mixture of phase regions for all of the samples according to the XRD measurements. Annealing temperature also has an effect on formation of this phase, widening its formation range. When the heat treatment temperature is increased from $750^{\circ} \mathrm{C}$ to $800^{\circ} \mathrm{C}$, composition range that $\beta$ phase obtained widened from $3-6$ mole $\%$ to $2-7$ mole $\%$ addition. XRD patterns of 4 mole $\% \mathrm{Eu}_{2} \mathrm{O}_{3}$ (after heating at $800^{\circ} \mathrm{C}$ and $750^{\circ} \mathrm{C}$, for $48 \mathrm{~h}$ ) were given in figure 1 . XRD patterns of other samples in these solid solution ranges were quite similar to the pattern given in this figure. All of the XRD peaks of the single phase samples were indexed in the tetragonal crystal symmetry and unit cell parameters were calculated and are given in figure 2. XRD measurements revealed that doping with more than 6 or 7 mole $\%$ $\mathrm{Eu}_{2} \mathrm{O}_{3}$ and less than 2 or 3 mole $\% \mathrm{Eu}_{2} \mathrm{O}_{3}$, depending on the heat treatment temperature, had produced the heterogeneous solid mixture of $\mathrm{Bi}_{2} \mathrm{O}_{3}$ polymorphs. These multiphase samples were excluded from this study.

Figures $2 \mathrm{a}$ and $\mathrm{b}$ show dependence of lattice parameters $a$ and $c$, respectively on addition ratio of $\mathrm{Eu}_{2} \mathrm{O}_{3}$. It is evident from XRD data that Eu ions are incorporated in the crystal structure of $\beta-\mathrm{Bi}_{2} \mathrm{O}_{3}$ since the lattice parameters display a systematic variation. Lattice parameters showed a slight but continuous increase with increasing $\mathrm{Eu}_{2} \mathrm{O}_{3}$ content. Therefore, we concluded that the solubility range for $\mathrm{Eu}_{2} \mathrm{O}_{3}$ in tetragonal type $\left(\mathrm{Bi}_{2} \mathrm{O}_{3}\right)_{1-x}\left(\mathrm{Eu}_{2} \mathrm{O}_{3}\right)_{x}$ solid solution were $0.03 \leq x \leq 0.06$ at $750^{\circ} \mathrm{C}$ and $0.02 \leq x \leq 0.07$ at $800^{\circ} \mathrm{C}$. The slight increase of lattice parameters with increasing $\mathrm{Eu}_{2} \mathrm{O}_{3}$ content was in good agreement with effective ionic radii considerations. Reported ionic radii

Table 1. The observed phases in the system $\left(\mathrm{Bi}_{2} \mathrm{O}_{3}\right)_{1-x}\left(\mathrm{Eu}_{2} \mathrm{O}_{3}\right)_{x}, x$ being $0 \cdot 01 \leq x \leq 0 \cdot 10$.

\begin{tabular}{lccccccccccc}
\hline & \multicolumn{10}{c}{ Mole $\% \mathrm{Eu}_{2} \mathrm{O}_{3}$ addition } \\
\cline { 2 - 12 } Temperature $\left({ }^{\circ} \mathrm{C}\right)$ & 1 & 2 & 3 & 4 & 5 & 6 & 7 & 8 & 9 & 10 \\
\hline 700 & $\alpha+\beta$ & $\alpha+\beta$ & $\alpha+\beta$ & $\alpha+\beta$ & $\alpha+\beta$ & $\alpha+\beta$ & $\alpha+\beta$ & $\alpha+\beta$ & $\alpha+\beta$ & $\alpha+\beta$ \\
750 & $\alpha+\beta$ & $\alpha+\beta$ & $\beta$ & $\beta$ & $\beta$ & $\beta$ & $\alpha+\delta$ & $\alpha+\delta$ & $\alpha+\delta$ & $\alpha+\beta$ \\
800 & $\alpha+\beta$ & $\beta$ & $\beta$ & $\beta$ & $\beta$ & $\beta$ & $\beta$ & $\delta+\gamma$ & $\delta+\gamma$ & $\delta+\gamma$ \\
830 wq* $^{*}$ & $\alpha+\beta$ & $\alpha+\beta$ & $\alpha+\beta$ & $\alpha+\beta$ & $\alpha+\beta$ & $\alpha+\beta$ & $\alpha+\beta$ & $\alpha+\delta$ & $\alpha+\delta$ & $\alpha+\delta$ \\
\hline
\end{tabular}

*Water quench. 
are $0.102 \mathrm{~nm}$ for $\mathrm{Bi}^{3+}, 0 \cdot 109 \mathrm{~nm}$ for $\mathrm{Eu}^{2+}$ and $0.095 \mathrm{~nm}$ for $\mathrm{Eu}^{3+}$ (West 1998; Misra and Andronenko 2000). When $\mathrm{Eu}^{2+}$ ions replace $\mathrm{Bi}^{3+}$ ions, lattice parameters should enlarge $\left(\mathrm{Bi}^{3+}\right.$ ion has smaller ionic radii than $\mathrm{Eu}^{2+}$ ions) and this enlargement should be about $0.069 \%$ for $1 \%$ replacement. These figures are consistent with our observations on lattice parameter changes. Elongation of $a$ when addition of $\mathrm{Eu}_{2} \mathrm{O}_{3}$ is increased from 2 mole $\%$ to 7 mole\% is about $0.62 \%$, on the other hand elongation of $c$ under the same conditions is almost half being about $0 \cdot 36 \%$. This indicates the possibility of localization of oxygen deficiency defects on $a-a$ related planes in the crystal structure since the enlargement along the $c$ axis is closer to the value obtained through ionic radii considerations. When lattice parameters in figure 2 are considered, ratio of the lattice parameters $(a / c)$ is increased with increasing addition ratio showing an enhanced tetragonality. Further, evidence for oxygen non-stoichiometry is discussed later in the text.

On the other hand, formation of tetragonal type $\left(\mathrm{Bi}_{2} \mathrm{O}_{3}\right)_{1-x}\left(\mathrm{Eu}_{2} \mathrm{O}_{3}\right)_{x}$ solid solution was a very slow process requiring a long heat treatment duration. It was concluded from this fact that diffusion rate for europium ions into bismuth trioxide was quite low. Through this slow diffusion mechanism, Eu cations preferentially substituted bismuth cations in the crystal structure. Although valence number of Eu cation is +3 in pure $\mathrm{Eu}_{2} \mathrm{O}_{3}$, these incorporated $\mathrm{Eu}$ ions would probably be reduced to bivalent state in the structure of obtained tetragonal type solution. When the charge balance is considered, as the addition of $\mathrm{Eu}_{2} \mathrm{O}_{3}$ increased, $\mathrm{O}^{2-}$ ions should spontaneously be oxidized to $\mathrm{O}_{2}$ molecules. As a result of this possible mechanism, some oxygen ion vacancies should occur at

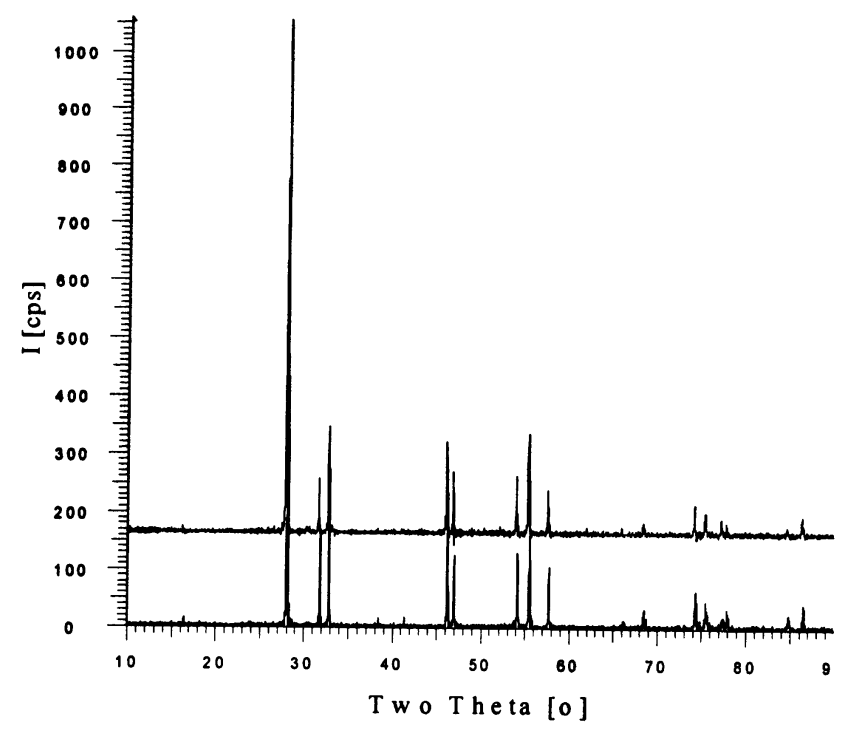

Figure 1. XRD pattern of $\beta-\mathrm{Bi}_{2} \mathrm{O}_{3}$ doped with 4 mole $\% \mathrm{Eu}_{2} \mathrm{O}_{3}$ (above pattern: after heating at $750^{\circ} \mathrm{C}$, below pattern: after heating at $800^{\circ} \mathrm{C}$ ). the $\mathrm{O}^{2-}$ sublattices in the tetragonal $\left(\mathrm{Bi}_{2} \mathrm{O}_{3}\right)_{1-x}\left(\mathrm{Eu}_{2} \mathrm{O}_{3}\right)_{x}$ solution. At the end of this, obtained solid solution should have the non-stoichiometric character and defect tetragonal structure. The non-stoichiometry for formed samples in this study can be regarded as an oxygen deficiency type as seen in the phases prepared by Gattow and Schütze (1964), Harwig (1978) and Medernach and Snyder (1978). Therefore, the composition of the $\beta$ type $\left(\mathrm{Bi}_{2} \mathrm{O}_{3}\right)_{1-x}$ $\left(\mathrm{Eu}_{2} \mathrm{O}_{3}\right)_{x}$ solution can be expressed as

$$
\mathrm{Bi}(\mathrm{III})_{2-2 x} \mathrm{Eu}(\mathrm{II})_{2 x} \mathrm{O}_{3-x} \text {, }
$$

where $x$ denotes oxygen ion vacancy. $x$ values are $0.03 \leq$ $x \leq 0.06$ for $750^{\circ} \mathrm{C}$ and $0.02 \leq x \leq 0.07$ for $800^{\circ} \mathrm{C}$ annealing temperatures.

The calculated weight ratio values obtained using the approximations outlined above are given in table 2, together with values obtained from SEM microprobe analysis. The values of wt $\% \mathrm{Bi}$ and wt $\%$ Eu were calculated according to non-stoichiometric formula. These measured values are
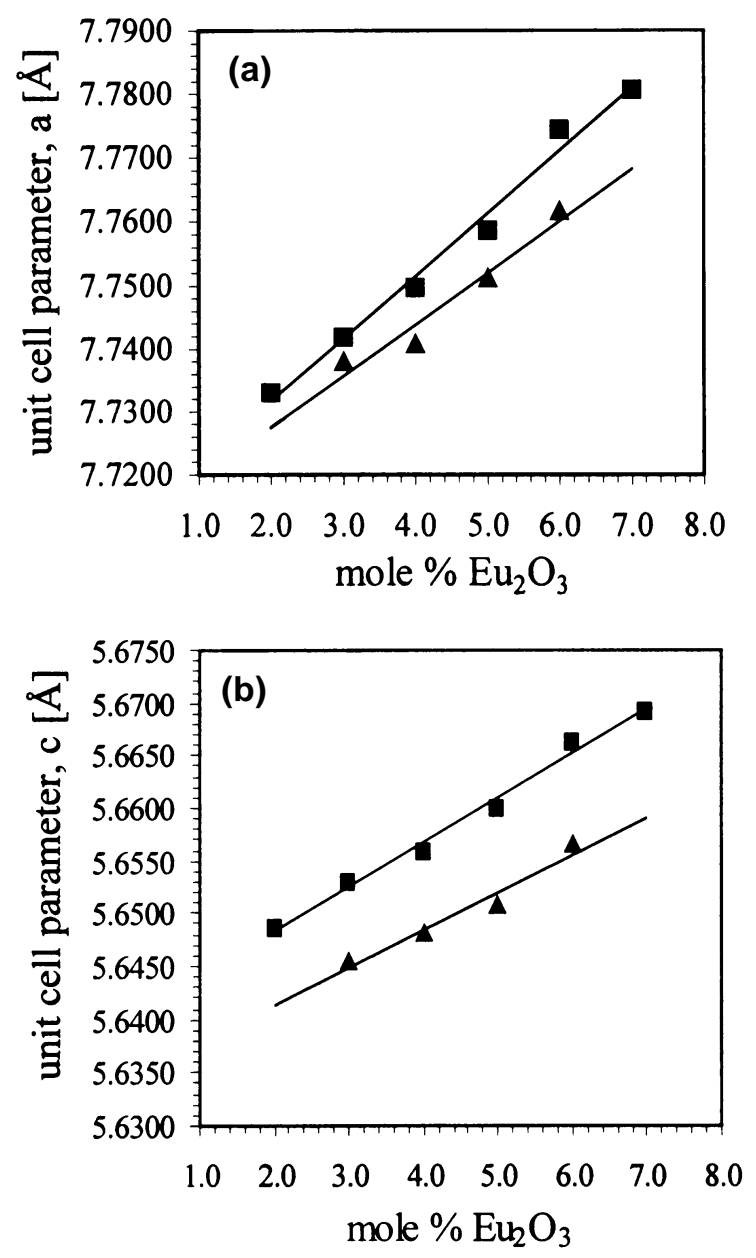

Figure 2. The relationship between the amount of $\mathrm{Eu}_{2} \mathrm{O}_{3}$ doping, and the lattice parameter of $\beta-\mathrm{Bi}_{2} \mathrm{O}_{3}$ : (a) Unit cell parameter, $a$ and (b) unit cell parameter, $c(\mathbf{\square}$, after heating at $750^{\circ} \mathrm{C} ; \boldsymbol{\Delta}$, after heating at $800^{\circ} \mathrm{C}$ ). 
in good agreement with the calculated ones. Cation concentrations higher than the expected stoichiometric values indicate oxygen deficiency in the crystal structure. Although this is not a solid proof for oxygen deficiency, it nevertheless is in agreement with the literature cited in the introduction. This oxygen deficiency may lead to variations in the electrical conductivity properties of these doped samples. When the data given in table 2 for samples annealed at two different temperatures $\left(750^{\circ} \mathrm{C}\right.$ and $800^{\circ} \mathrm{C}$ ) were compared, no significant or systematic difference was present.

The colour of our annealed samples had a systematic change depending on the amount of europium trioxide addition. The colour of the sintered powder specimens was light yellow for $1 \%, 8 \%$ and $9 \%$ additions where single $\beta$ phase is not obtained. As $\beta$ type solid solution is formed with increasing addition ratio, the colour of the powder changed to red brown which is a darker colour. The observed colour change phenomenon provides further support for non-stoichiometry in our samples since nonstoichiometry causes darkening.

Table 3 shows the results of the grain size calculations from XRD data. There is a general tendency that grain size becomes smaller with increasing addition ratio. These peaks used for calculations were sharpest and symmetri- cal, (201) having the highest intensity. We have also observed that grain sizes of the samples annealed at $800^{\circ} \mathrm{C}$ are slightly smaller than the samples annealed at $750^{\circ} \mathrm{C}$.

SEM investigation of the ground powders and fracture surfaces showed that grain size distribution was not uniform. We observed sub micron grains (finely ground powder) as well as grains above even $10 \mu$ (fracture surfaces). XRD patterns were taken from finely ground powder which mostly had sub micron grain size. Connectivity of the grains is improved when $\mathrm{Eu}_{2} \mathrm{O}_{3}$ addition is increased. Outer free surfaces of the samples annealed at $750^{\circ} \mathrm{C}$ in air were examined and shown in figure 3. Outer surface of the sample with $1 \% \quad \mathrm{Eu}_{2} \mathrm{O}_{3}$ addition had smoother appearance and sharper grain boundaries. Sharpness of the grain boundaries gradually decreased while grain connectivity is improved as the addition ratio increased. At the same time, as the tetragonal $\beta$ phase is formed, more voids appeared on the sample. Sample with higher $\mathrm{Eu}_{2} \mathrm{O}_{3}$ addition had more cracks on the surface and these cracks probably were due to shrinkage during heat treatment. As seen in SEM pictures (figure 4) of fracture surfaces of tablets annealed at $750^{\circ} \mathrm{C}$, there are much more microcracks in $6 \% \mathrm{Eu}_{2} \mathrm{O}_{3}$ added sample compared with $4 \% \mathrm{Eu}_{2} \mathrm{O}_{3}$ added sample. Deterioration of the microstructure of the $6 \% \mathrm{Eu}_{2} \mathrm{O}_{3}$ added sample is also apparent

Table 2. The microprobe analysis for the tetragonal $(\beta)$ type solid solution of $\left(\mathrm{Bi}_{2} \mathrm{O}_{3}\right)_{1-x}$ $\left(\mathrm{Eu}_{2} \mathrm{O}_{3}\right)_{x}$ system.

\begin{tabular}{|c|c|c|c|c|c|c|}
\hline \multirow[b]{2}{*}{$x$} & \multicolumn{2}{|c|}{ After heating at $750^{\circ} \mathrm{C}$} & \multicolumn{2}{|c|}{ After heating at $800^{\circ} \mathrm{C}$} & \multicolumn{2}{|c|}{ Calculated } \\
\hline & $\mathrm{wt} \% \mathrm{Bi}$ & $\mathrm{wt} \% \mathrm{Eu}$ & $\mathrm{wt} \% \mathrm{Bi}$ & $\mathrm{wt} \% \mathrm{Eu}$ & $\mathrm{wt} \% \mathrm{Bi}$ & $\mathrm{wt} \% \mathrm{Eu}$ \\
\hline $0 \cdot 02$ & $(-)^{*}$ & $(-)^{*}$ & $88 \cdot 72 \pm 0 \cdot 26$ & $1 \cdot 25 \pm 0 \cdot 12$ & $88 \cdot 40$ & $1 \cdot 31$ \\
\hline 0.03 & $87 \cdot 63 \pm 0.36$ & $1.92 \pm 0.07$ & $88 \cdot 14 \pm 0 \cdot 22$ & $1 \cdot 82 \pm 0 \cdot 15$ & $87 \cdot 74$ & 1.97 \\
\hline 0.04 & $87 \cdot 34 \pm 0 \cdot 19$ & $2 \cdot 48 \pm 0 \cdot 10$ & $87 \cdot 42 \pm 0 \cdot 29$ & $2 \cdot 44 \pm 0 \cdot 11$ & $87 \cdot 08$ & $2 \cdot 64$ \\
\hline 0.05 & $86 \cdot 84 \pm 0 \cdot 13$ & $3 \cdot 01 \pm 0 \cdot 11$ & $86 \cdot 65 \pm 0 \cdot 16$ & $3 \cdot 10 \pm 0 \cdot 12$ & $86 \cdot 42$ & $3 \cdot 31$ \\
\hline 0.06 & $86 \cdot 37 \pm 0 \cdot 31$ & $3 \cdot 65 \pm 0 \cdot 23$ & $85 \cdot 73 \pm 0.33$ & $3 \cdot 88 \pm 0 \cdot 16$ & $85 \cdot 75$ & $3 \cdot 98$ \\
\hline $0 \cdot 07$ & $(-)^{*}$ & $(-)^{*}$ & $85 \cdot 42 \pm 0.23$ & $4 \cdot 24 \pm 0 \cdot 22$ & $85 \cdot 08$ & $4 \cdot 66$ \\
\hline
\end{tabular}

* Single $\beta$ phase could not be observed.

Table 3. Effect of doping ratio of $\mathrm{Eu}_{2} \mathrm{O}_{3}$ on grain size.

\begin{tabular}{|c|c|c|c|c|c|c|c|c|}
\hline \multirow[b]{3}{*}{$x$} & \multicolumn{8}{|c|}{ Grain size for the planes (nm) } \\
\hline & \multicolumn{4}{|c|}{ After heating at $750^{\circ} \mathrm{C}$} & \multicolumn{4}{|c|}{ After heating at $800^{\circ} \mathrm{C}$} \\
\hline & $(201)$ & $(002)$ & (203) & $(421)$ & $(201)$ & $(002)$ & $(203)$ & $(421)$ \\
\hline 0.02 & $(-)^{*}$ & $(-)^{*}$ & $(-)^{*}$ & $(-)^{*}$ & $208 \cdot 6$ & $178 \cdot 3$ & $157 \cdot 8$ & $169 \cdot 6$ \\
\hline 0.03 & $242 \cdot 0$ & $187 \cdot 3$ & 228.4 & $192 \cdot 0$ & $204 \cdot 4$ & $170 \cdot 3$ & $148 \cdot 1$ & $137 \cdot 4$ \\
\hline 0.04 & $226 \cdot 2$ & $174 \cdot 0$ & $215 \cdot 8$ & $181 \cdot 5$ & $200 \cdot 6$ & $153 \cdot 9$ & $122 \cdot 4$ & $135 \cdot 5$ \\
\hline $0 \cdot 05$ & $213 \cdot 1$ & $161 \cdot 2$ & $146 \cdot 8$ & $151 \cdot 2$ & $197 \cdot 0$ & $141 \cdot 9$ & $111 \cdot 4$ & $113 \cdot 8$ \\
\hline 0.06 & $193 \cdot 8$ & $148 \cdot 8$ & $113 \cdot 1$ & $135 \cdot 2$ & $188 \cdot 7$ & $134 \cdot 3$ & $88 \cdot 8$ & $88 \cdot 3$ \\
\hline 0.07 & $(-)^{*}$ & $(-)^{*}$ & $(-)^{*}$ & $(-)^{*}$ & $179 \cdot 2$ & $99 \cdot 1$ & $64 \cdot 1$ & $80 \cdot 7$ \\
\hline
\end{tabular}

* Single $\beta$ phase could not be observed. 

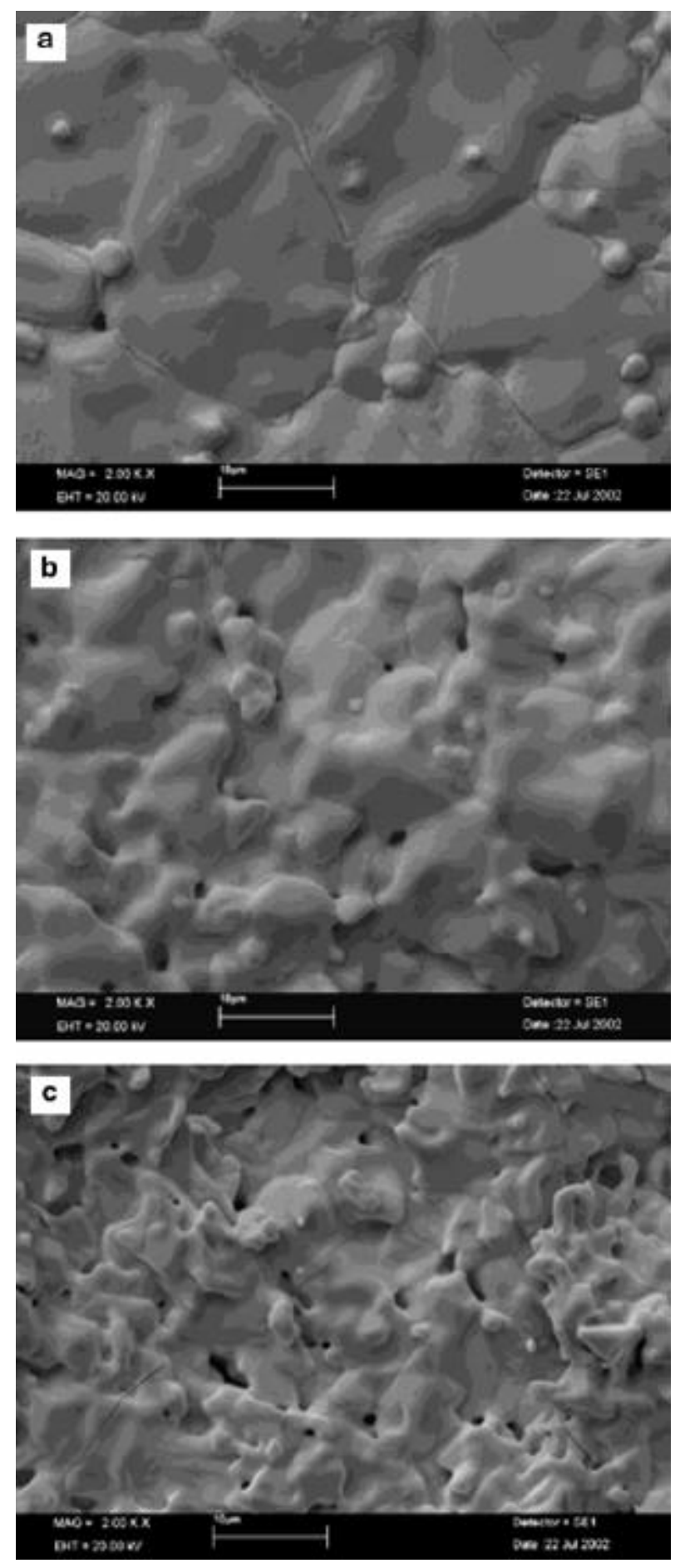

Figure 3. a, b and $\mathbf{c}$ show the outer free surface of the annealed samples $\left(750^{\circ} \mathrm{C}\right)$ at the same magnification for 1,3 and $5 \% \mathrm{Eu}$ addition ratios, respectively.

in this figure. This $6 \% \mathrm{Eu}_{2} \mathrm{O}_{3}$ addition ratio is the limit for the formation of $\beta$ phase for this annealing temperature. Very good grain connectivity is seen in the micrograph of the fracture surface of the $4 \% \quad \mathrm{Eu}_{2} \mathrm{O}_{3}$ added sample. Microvoids mentioned earlier are also seen in SEM pictures of the fracture surface of both samples.
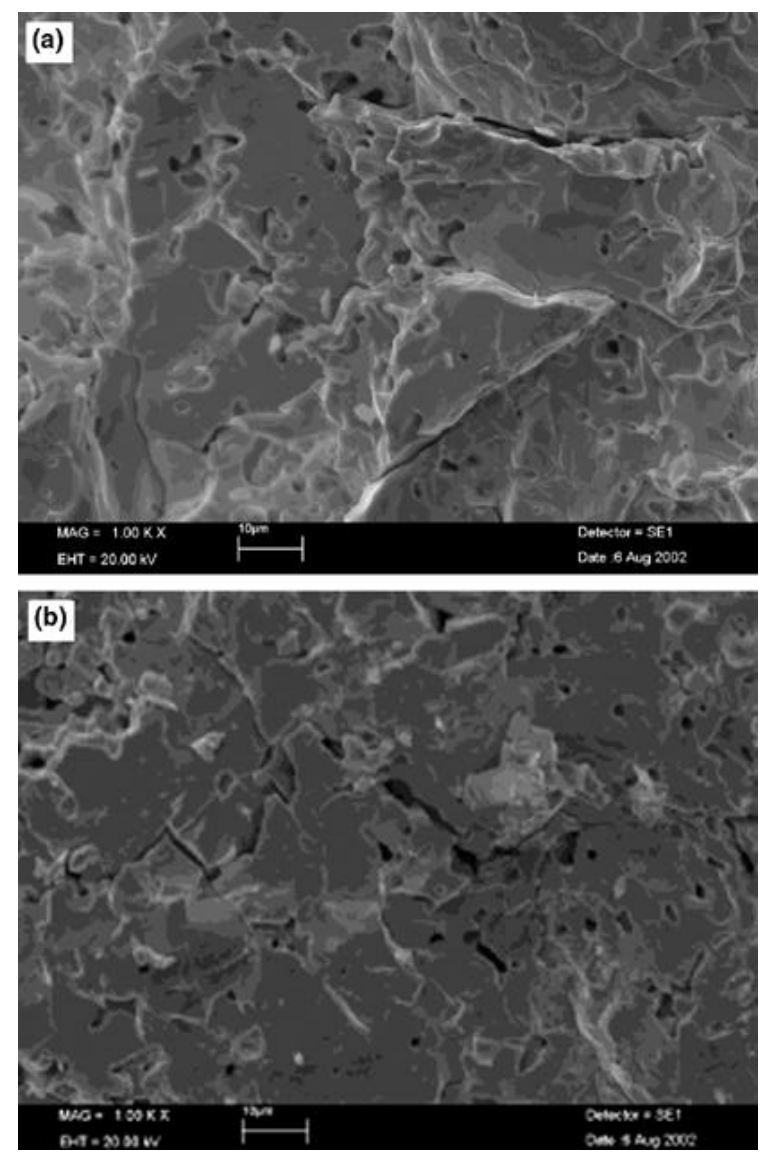

Figure 4. Fracture surfaces of the samples with $4 \% \mathrm{Eu}$ addition (a) and $6 \%$ Eu addition (b).

\section{Conclusions}

Metastable $\beta$ phase of $\mathrm{Bi}_{2} \mathrm{O}_{3}$ polymorph and related solid solution have been obtained through solid state reaction techniques at room temperature stable phases by doping pure monoclinic $\alpha-\mathrm{Bi}_{2} \mathrm{O}_{3}$ material with $\mathrm{Eu}_{2} \mathrm{O}_{3}$. Heat treatment temperature, annealing duration and amount of $\mathrm{Eu}_{2} \mathrm{O}_{3}$ are effective factors in synthesis of this polymorph. $\mathrm{Eu}^{2+}$ cations substituted $\mathrm{Bi}^{3+}$ cations in the crystal structure of $\beta$ phase. We concluded that the synthesized phase was non-stoichiometric for oxygen content. Higher doping rates introduce more defects into the structures and tetragonality is enhanced. The most predominant defects may be oxygen vacancies which increase with increasing amount of $\mathrm{Eu}_{2} \mathrm{O}_{3}$. We presume that oxygen nonstoichiometry of this material may lead to an interesting electrical conductivity behaviour.

\section{Acknowledgement}

Prof. Zeki Yilmaz, Rector of Erciyes University, is sincerely thanked for provision of the research facilities in Technology Research and Application Centre. 


\section{References}

Chiodelli G, Magistris A, Spinolo G, Tomasi C, Antonucci V and Giordano N 1994 Solid State Ionics 7437

France M R, Buchanan J W, Robinson J C, Pullins S H, Tucker J L, King R B and Duncan M A 1997 J. Phys. Chem. A101 6214

Gattow G and Schütze D 1964 Z. Anorg. Allg. Chem. 32844

Harwig H A 1978 Z. Anorg. Allg. Chem. 444151

Harwig H A and Gerards A G 1978 J. Solid State Chem. 26265

Ling C D, Withers R L, Schmid S and Thompson J G 1998 J. Solid State Chem. 13742

Medernach J W and Snyder R L 1978 J. Am. Ceram. Soc. 61 494
Misra S K and Andronenko S I 2000 J. Phys. Chem. Solids 61 1913

Miyayama M and Yanagida H 1986 J. Mater. Sci. 211233

Miyayama M, Katsuta S, Suenaga Y and Yanagida H 1982 J. Am. Ceram. Soc. 66585

Oniyama E and Wahlbeck P G 1998 J. Phys. Chem. B102 4418

Takahashi T, Esaka T and Iwahara H 1977 J. Appl. Electrochem. 731

Turkoglu O and Soylak M 2002 Asian J. Chem. 141698

Turkoglu O, Gümüs A and Belenli I 1998 Bal. Phys. Lett. 134

Turkoglu O, Soylak M and Külcü N 1999 Kuw. J. Sci. Eng. 26289

West A R 1988 Basic solid state chemistry (Chichester: John Wiley \& Sons) p. 390 